\title{
Protection of sensitive loads using sliding mode controlled three- phase DVR with adaptive notch filter
}

\author{
Samet Biricik \\ European University of Lefke, Via Mersin 10,Turkey, sbiricik@eul.edu.tr \\ Hasan Komurcugil \\ Eastern Mediterranean University - Cyprus \\ Nguyen Duc Tuyen \\ Hanoi University of Technology
}

See next page for additional authors

Follow this and additional works at: https://arrow.tudublin.ie/engscheleart2

Part of the Electrical and Computer Engineering Commons

\section{Recommended Citation}

S. Biricik, H. Komurcugil, N. D. Tuyen and M. Basu, "Protection of Sensitive Loads Using Sliding Mode Controlled Three-Phase DVR With Adaptive Notch Filter," in IEEE Transactions on Industrial Electronics, vol. 66, no. 7, pp. 5465-5475, July 2019, doi: 10.1109/TIE.2018.2868303.

This Article is brought to you for free and open access by the School of Electrical and Electronic Engineering at ARROW@TU Dublin. It has been accepted for inclusion in Articles by an authorized administrator of ARROW@TU Dublin. For more information, please contact arrow.admin@tudublin.ie, aisling.coyne@tudublin.ie, gerard.connolly@tudublin.ie.

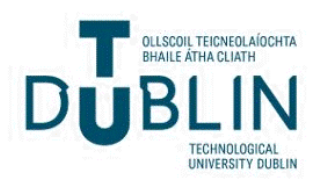




\section{Authors}

Samet Biricik, Hasan Komurcugil, Nguyen Duc Tuyen, and Malabika Basu

This article is available at ARROW@TU Dublin: https://arrow.tudublin.ie/engscheleart2/267 


\title{
Protection of Sensitive Loads Using Sliding Mode Controlled Three-Phase DVR With Adaptive Notch Filter
}

\author{
Samet Biricik ${ }^{(1)}$, Member, IEEE, Hasan Komurcugil ${ }^{\circledR}$, Senior Member, IEEE, \\ Nguyen Duc Tuyen (), and Malabika Basu (), Member, IEEE
}

\begin{abstract}
This paper introduces a sliding mode control (SMC) strategy for three-phase dynamic voltage restorers (DVRs) with a 12-switch voltage source inverter. The compensating voltage references needed in the SMC strategy are generated by an adaptive notch filter (ANF), which exhibits excellent performance under grid voltage anomalies such as voltage sags, swells, and unbalanced and distorted grid voltage conditions. The consequence of using the ANF eliminates the use of phase-lock loop or frequency-lock loop and low-pass filter, which makes it distinguishable from the existing reference signal generation solutions. In addition, the use of the SMC strategy with its attractive properties makes the control implementation simple. Theoretical results are supported by simulation results as well as realtime laboratory results over a range of grid voltage anomalies. These results show that the proposed control strategy not only offers an excellent dynamic response independent from the parameter variations and disturbances but also compensates the voltage sags, swells, and harmonics on the load terminals under the defined limits of the IEEE-519 standard.
\end{abstract}

Index Terms-Adaptive notch filter (ANF), dynamic voltage restorer (DVR), sliding mode controller, voltage sag, voltage swell.

\section{INTRODUCTION}

$\mathbf{T}$ HE commercial and industrial consumers of electrical power penetrated into the distribution system are increasingly demanding a better power quality. The voltage distortions and fluctuations existing in the distribution system may

Manuscript received August 4, 2017; revised January 18, 2018 and June 30, 2018; accepted August 14, 2018. Date of publication September 14, 2018; date of current version February 28, 2019. (Corresponding author: Hasan Komurcugil.)

$\mathrm{S}$. Biricik is with the Department of Electrical and Electronic Engineering, European University of Lefke, Lefke 99728, Turkey, and also with the School of Electrical and Electronic Engineering, Dublin Institute of Technology, Dublin D08 X622, Ireland (e-mail: sbiricik@eul.edu.tr).

$\mathrm{H}$. Komurcugil is with the Computer Engineering Department, Eastern Mediterranean University, Famagusta 99450, Turkey (e-mail: hasan.komurcugil @emu.edu.tr).

N. D. Tuyen is with the Shibaura Institute of Technology, Tokyo 1358548, Japan, and also with Hanoi University of Science and Technology, Hanoi 10000, Vietnam (e-mail: m609504@ shibaura-it.ac.jp).

M. Basu is with the School of Electrical and Electronic Engineering, Dublin Institute of Technology, D08 X622, Dublin, Ireland (e-mail: mbasu@ieee.org).

Color versions of one or more of the figures in this paper are available online at http://ieeexplore.ieee.org.

Digital Object Identifier 10.1109/TIE.2018.2868303 adversely affect the sensitive loads like computing equipment, communication system, manufacturing process, and adjustable speed drives. The voltage sag and swell problems arise by shortcircuit faults in the system.

In the case of the voltage sags, operation of the sensitive loads employed in the industry are highly affected, which results in significant costs because of the production loss. In the literature, voltage sag and swell problems are described as an abrupt reduction or rise of the voltages varying from $10 \%$ to $90 \%$ during sag and $110 \%$ to $180 \%$ during swell of its nominal value [1]. Besides these, because of the nonlinear loads such as motor drives or power electronics devices, the load currents may contain current harmonic components. These currents, in turn, interact with the distribution line impedances and then distort the voltages at the load terminals.

In order to cope with these problems, dynamic voltage restorers (DVRs) are widely used in the industry [2], [3]. A properly designed DVR not only solves the voltage-related power quality problems but also eliminates the source harmonic voltages on the load terminals [4]. Therefore, the main objective of a DVR is to inject a voltage in series with the grid voltage to keep the load voltage at a required level for all times. In order to accomplish this objective, the DVR should be controlled by an appropriate control strategy capable of offering a fast dynamic response, high robustness to parameter variations, sinusoidal load voltage with low total harmonic distortion (THD), and small steadystate errors. In addition, its performance under distorted grid voltage conditions should be quite good so as to maintain the load voltage at the required level.

Some of the control strategies are developed to compensate the voltage sags only [1], [5]-[7]. On the other hand, the control strategies proposed in [8]-[10] are able to compensate the voltage sags and voltage swells as well as the harmonics that arise during the distorted grid. In most of the existing control methods devised for the DVRs, the synchronously rotating $d q$ reference frame algorithm has been widely used to detect the voltage differences and to access the $d q$ components of the voltages. However, Bae et al. [10] reported that the $d q$ algorithm does not offer the possibility of detecting different frequency components. Also, it is unable to satisfy the required control objective during waveform distortions and unbalanced voltage sag conditions. Although the idea of an adaptive notch filter (ANF) has already been employed in the control of the active 
power filter in [11] and [12] with the aim of filtering the current harmonics, its performance in the control of the DVR has not been yet studied. The ANF method with its excellent ability in extracting positive-sequence components from nonideal signal was applied in both 3P3W system [11] and 3P4W system [12] as alternatives for a conventional $d q$-filter. Those studies also show that the ANF can be implemented in either $\alpha \beta 0$ - or $a b c$-coordinate system. Owing to the fast response and robust dynamic performance, the ANF method can be utilized in some applications with high disturbances and signal pollution, which eliminates the requirement of any high-pass or low-pass filtering as otherwise required by the conventional methods.

It is well-known that the control strategy is as important as the inverter topology that affects the cost, steady-state, and dynamic performances of the device. The sliding mode control (SMC) technique has received considerable attention in recent years due to its important advantages such as the strong robustness against parameter variations and disturbances, simplicity in implementation, fast dynamic response, and guaranteed stability. The SMC technique with these advantages is successfully applied to the control of UPS inverters [13], [14], dc-dc buck converters [15], [16], and three-phase DVRs with a transformer [17], and without a transformer [18]. In all of these works, it is mentioned that the value of sliding constant (referred to as $\lambda$ ) determines the speed of the dynamic response and existence region size of the sliding mode. While small valued sliding constant causes a slow dynamic response, large valued sliding constant may lead to undesirable overshoots. The rotating sliding-line-based SMC with a time-varying sliding constant improves the dynamic response without paying attention to the existence region of the sliding mode [14]. In all of the existing SMC strategies, the selection of sliding constant is based on the trial and error method without paying attention to the existence region. Recently, Biricik and Komurcugil [19] established the relationship between the dynamic response and existence region of the sliding mode for a single-phase DVR.

In this paper, an SMC-based control strategy in which the references of the compensation voltages are determined by the ANF is proposed for a three-phase DVR employing a 12 -switch voltage source inverter (VSI). The proposed control strategy offers fast dynamic response, on-line estimation of the voltage anomalies on the grid voltages, strong robustness to voltage sags and swells, and simplicity in implementation. In 12-switch DVR topology, instead of using a threephase transformer, three single-phase transformers are used with the aim of reducing zero-sequence components. Moreover, this combination increases the flexibility and reliability of the system.

The organization of this paper is as follows. The studied DVR topology is introduced in Section II. The sliding mode controller with the determination of its existence regions and ANF are given in Section III. The simulations and experimental results are included in Sections IV and V. Finally, comparisons of the proposed method with the state-of-the-art are presented in Section VI, and the conclusion is presented in Section VII.

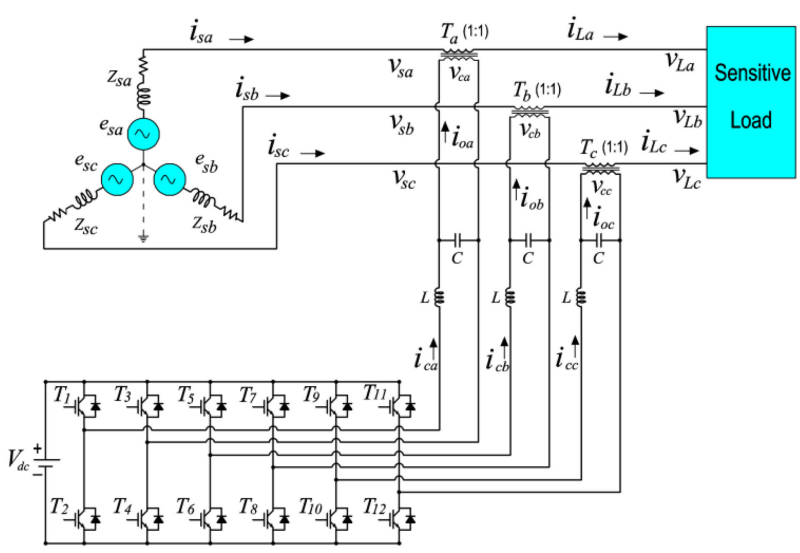

Fig. 1. Three-phase DVR with the 12-switch VSI.

\section{DVR WITH THE 12-SWITCH VSI}

The circuit of the studied DVR is a three-phase 12-switch VSI with an energy storage battery, as shown in Fig. 1. The energy storage is required to provide real power to the load during voltage injection into the grid. The lead-acid batteries are good storage devices, which can be used in DVR applications [21]-[23]. One of the main advantages of using a common battery source at the dc-link is that the dc-link voltage regulation with the additional control algorithm is not required.

The common inverter topologies of the three-phase DVR can be classified as 6-switch three-phase inverter, 6-switch threephase inverter with split capacitor, and 12-switch three-phase inverter. Although the 6-switch three-phase DVR has the simplest inverter topology with the minimum switches, this topology is unable to operate under unbalanced sag and swell voltage condition. The 6-switch three-phase inverter with split-capacitor topology requires additional control loop to balance the capacitor voltages. Moreover, compensation duration voltage compensation percentages are limited. Therefore, 12-switch three-phase inverter topology is the best candidate for compensating voltage swells and sags under unbalanced conditions. A detailed comparison between three-phase DVR topologies is presented in [24]. In the 12-switch DVR topology, the output of each 4switch inverter is connected to the point of common coupling (PCC) through a low-frequency single-phase transformer, which achieves the galvanic isolation. The primary side of each transformer is connected between the utility and load line in series on each phase. In the conventional three-phase DVRs employing the 6-switch VSI, the secondary side of the transformer is required to be connected to the VSI as delta [20] or star [4], [8]. However, there is no such delta or star connection in the 12switch VSI. As shown in Fig. 1, the input and output terminals of the secondary side of the transformers are directly connected to the VSI terminals. Such converters are mostly preferred for the effective control on the zero-sequence components to cater for the unbalanced voltages or single-phase voltage sags. Therefore, this type of connection is very useful during the compensation of unbalanced utility voltages. 


\section{Proposed Control Strategy}

In the literature, there are many control strategies devised for DVRs. Generally, these control strategies involve three main objectives such as the detection of voltage anomalies, generation of the reference signals needed for controlling the DVR, and suitable controller. In this study, the detection of voltage anomalies and generation of the reference signals are achieved by using the ANF. The control of the DVR is based on the SMC.

\section{A. Sliding Mode Control}

The switching devices shown in Fig. 1 should be operated such that the DVR injects the desired compensation voltage $\left(v_{c p}\right)$ in series with the grid voltage $\left(v_{s p}\right)$ through a series transformer $T_{p}(1: 1)$ for each phase. The transformer is used to provide an electrical isolation between the VSI and grid. The grid impedance is represented by $Z_{s p}$. The differential equations regarding the operation of DVR can be written as

$$
\begin{aligned}
k i_{c p} & =\left(u_{p} V_{\mathrm{dc}}-v_{c p}\right) / L \\
k v_{c p} & =\left(i_{c p}-i_{s p}\right) / C
\end{aligned}
$$

where $k=d / d t, i_{c p}$ is the inductor current, $i_{s p}$ is the supply current, $v_{c p}$ is the compensation voltage, $V_{\mathrm{dc}}$ is the chargeable dc power supply, $L$ is the filter inductance, $C$ is the filter capacitance, $u_{p}$ is the control input, and $p=a, b, c$. The design of SMC is based on two important steps: determination of suitable sliding surface function and selection of suitable control law. The VSI topology used in this study is buck type (input de voltage is always greater than the peak value of inverter's output voltage). Since the main goal here is to control inverter's output voltage, which is the compensation voltage in the DVR, then using the compensation voltage error and its rate of change as the state variables for this inverter topology is the simplest and effective method in an SMC application [13], [14]. It is worth noting that using the inverter current error and compensation voltage error as the state variables would also yield satisfactory performance at the expense of increased controller complexity and cost due to the inverter current sensing requirement.

Now, let the compensation voltage error and its derivative be defined as

$$
x_{1 p}=v_{c p}-v_{c p}^{*}, \quad x_{2 p}=\dot{x}_{1 p}=\dot{v}_{c p}-\dot{v}_{c p}^{*}
$$

where $v_{c p}^{*}$ is the reference for the compensating voltage, $\dot{x}_{1 p}$ is the derivative of $x_{1 p}$, and $\dot{v}_{c p}$ is the derivative of $v_{c p}$. It is obvious from (3) that $v_{c p}^{*}$ is needed whose generation will be discussed in Section III-B. Taking derivative of $x_{1 p}$ and $x_{2 p}$ yields

$$
\dot{x}_{1 p}=x_{2 p}=\dot{v}_{c p}-\dot{v}_{c p}^{*}, \quad \dot{x}_{2 p}=\ddot{v}_{c p}-\ddot{v}_{c p}^{*} .
$$

Substituting (2) into $\dot{x}_{2 p}$ yields

$$
\dot{x}_{2 p}=-k \dot{v}_{c p}^{*}+\left(k i_{c p}-k i_{s p}\right) / C .
$$

Now, substituting (1) into (5), using $v_{c p}=x_{1 p}+v_{c p}^{*}$ and $\omega_{s}^{2}=1 / L C$ in the resulting equation gives

$$
\dot{x}_{2 p}=-\omega_{s}^{2} x_{1 p}+\omega_{s}^{2} u_{p} V_{\mathrm{dc}}-\omega_{s}^{2} v_{c p}^{*}-k \dot{v}_{c p}^{*}-\left(k i_{s p}\right) / C .
$$

Hence, the behavior of the DVR in terms of $x_{1 p}$ and $x_{2 p}$ can be written as

$$
\begin{aligned}
& \dot{x}_{1 p}=x_{2 p} \\
& \dot{x}_{2 p}=\omega_{s}^{2}\left[u_{p} V_{\mathrm{dc}}-x_{1 p}+D_{p}(t) V_{\mathrm{dc}}\right]
\end{aligned}
$$

where $D_{p}(t)$ is the disturbance described as

$$
D_{p}(t)=\left(-L k i_{s p}-v_{c p}^{*}-L C k \dot{v}_{c p}^{*}\right) / V_{\mathrm{dc}} .
$$

From (9), it can be seen that $D_{p}(t)$ is a time-varying function. The sliding surface function is defined as

$$
S_{p}=\lambda x_{1 p}+x_{2 p}
$$

where $\lambda$ is the positive sliding constant. The system enters into the sliding mode when $S_{p}=\dot{S}_{p}=0$. In this case, the error variables are enforced to slide on the sliding surface toward the origin $\left(x_{1 p}=0\right.$ and $\left.x_{2 p}=0\right)$. The sliding mode is defined by the following equation:

$$
\dot{x}_{1 p}=x_{2 p}=-\lambda x_{1 p} .
$$

The solution of (11) can easily be obtained as

$$
x_{1 p}=x_{1 p}(0) e^{-\lambda t} \text {. }
$$

In order to keep the movement of the error variables on the sliding surface, the following condition must hold:

$$
S_{p} \dot{S}_{p}<0 .
$$

Existence of the sliding mode is necessary due to the stability reason. Hence, if the control input $u_{p}$ is defined as

$$
u_{p}=-\operatorname{sign}\left(S_{p}\right)
$$

then the sliding mode exists if the following conditions are satisfied.

Condition I: When $S_{p}<0 \Rightarrow u_{p}=1$

$$
\dot{S}_{p}=-\omega_{s}^{2} x_{1 p}+\lambda x_{2 p}+d_{1 p}(t)>0 .
$$

Condition II: When $S_{p}>0 \Rightarrow u_{p}=-1$

$$
\dot{S}_{p}=-\omega_{s}^{2} x_{1 p}+\lambda x_{2 p}+d_{2 p}(t)<0 .
$$

Equations (15) and (16) represent two parallel lines, which constitute the boundaries of the existence region in the $\left(x_{1 p}, x_{2 p}\right)$ plane. In (15) and (16), $d_{1 p}(t)$ and $d_{2 p}(t)$ are defined as

$$
\begin{aligned}
& d_{1 p}(t)=\omega_{s}^{2} V_{\mathrm{dc}}+D_{p}(t) \\
& d_{2 p}(t)=-\omega_{s}^{2} V_{\mathrm{dc}}+D_{p}(t) .
\end{aligned}
$$

It is apparent from (12) that $\lambda$ controls the rate at which the compensation voltage error decays to zero. According to (15) and (16), $\lambda$ also determines the borders of the existence region (not shown due to limited space). This fact was already mentioned by Biricik and Komurcugil [19]. It is pointed out that while large $\lambda$ would speed up the dynamic response, it causes a reduction in the existence region size, which endangers the stability of the sliding mode. On the other hand, small $\lambda$ not only slows down the dynamic response but also reduces the size of the existence region. Hence, the value of $\lambda$ plays an important 


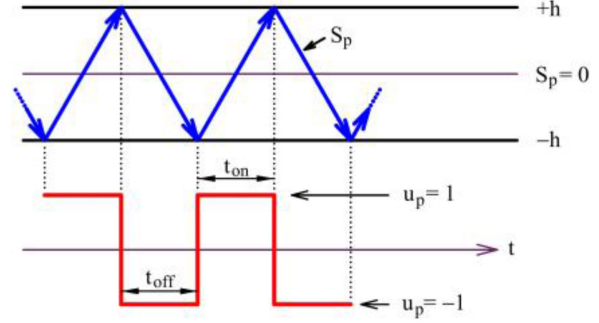

Fig. 2. Evolution of $S_{p}$.

role in determining the desired dynamic response speed and sufficiently large existence region, which ensures the stability. In most of the SMC studies published so far, the heuristic method is used to determine the optimum value of $\lambda$. Recently, Biricik and Komurcugil [19] proposed an analytical method to find the optimum value of $\lambda$, which maximizes the existence region and improves the dynamic response of the compensation voltage error. It is shown that the optimum value of $\lambda$ depends on the output $L C$ filter. In this study, the selection of $\lambda$ was based on the method introduced in [19].

\section{B. Analysis of Chattering}

The main drawback of the SMC approach is chattering, which appears as very high frequency oscillations caused by the ideal discontinuous control in (14). In order to suppress the chattering and avoid high switching frequency, (14) is modified with the hysteresis modulation using a hysteresis band as follows:

$$
u_{p}=\left\{\begin{array}{lll}
1 & \text { when } & S_{p}<-h \\
-1 & \text { when } & S_{p}>+h
\end{array}\right.
$$

where $h$ denotes the hysteresis band. Evolution of $S_{p}$ is shown in Fig. 2.

Clearly, the sliding surface function moves between the upper and lower hysteresis bands. In the sliding mode, assuming that $x_{1 p} \cong x_{2 p} \cong 0$, the derivative of (10) can be written as

$$
\dot{S}_{p} \cong \omega_{s}^{2} V_{\mathrm{dc}}\left(u_{p}+D_{p}(t)\right)
$$

where

$D_{p}(t)=-\frac{V_{c p}}{V_{\mathrm{dc}}}\left(1-\omega^{2} L C\right) \sin \left(\omega_{0} t\right)-\frac{\omega L I_{L p}}{V_{\mathrm{dc}}} \cos \left(\omega_{0} t-\psi\right)$.

In (21), the load current and compensation voltage reference are assumed to be $i_{L p}=I_{L p} \sin \left(\omega_{0} t-\psi\right)$ and $v_{c p}^{*}=$ $V_{c p} \sin \left(\omega_{0} t\right)$. The disturbance term $D_{p}(t)$ can be written in terms of a single cosine term as follows:

$$
D_{p}(t)=D_{m} \cos \left(\omega_{0} t-\phi\right)
$$

where

$$
\begin{aligned}
D_{m} & =\sqrt{D_{1}^{2}+D_{2}^{2}+2 D_{1} D_{2} \sin \psi} \\
D_{1} & =\frac{V_{c p}}{V_{\mathrm{dc}}}\left(1-\omega^{2} L C\right), \quad D_{2}=\frac{\omega L I_{L p}}{V_{\mathrm{dc}}} \\
\phi & =\tan ^{-1}\left(\left(D_{1}+D_{2} \sin \psi\right) / D_{2}\right) .
\end{aligned}
$$

Using the system parameters in the Appendix, $\phi$ is computed to be $86.56^{\circ}$, which can be approximated as $\phi \cong 90^{\circ}$. Hence, the disturbance can be written as

$$
D_{p}(t)=D_{m} \sin \left(\omega_{0} t\right)
$$

From Fig. 2, one can easily obtain

$$
\begin{aligned}
t_{\mathrm{on}} & =\frac{2 h}{\left.\dot{S}_{p}\right|_{u_{p}=1}}=\frac{2 h}{\omega_{s}^{2} V_{\mathrm{dc}}\left(1+D_{m} \sin \omega_{0} t\right)} \\
t_{\mathrm{off}} & =\frac{-2 h}{\left.\dot{S}_{p}\right|_{u_{p}=-1}}=\frac{2 h}{\omega_{s}^{2} V_{\mathrm{dc}}\left(1-D_{m} \sin \omega_{0} t\right)} .
\end{aligned}
$$

Now, the switching frequency can be easily written as

$$
f_{\mathrm{sw}}=\frac{\omega_{s}^{2} V_{\mathrm{dc}}}{4 h}\left(1-D_{m}^{2} \sin ^{2}\left(\omega_{0} t\right)\right) .
$$

It can be seen that $f_{\mathrm{sw}}=\infty$ under ideal discontinuous control ( $h=0$ ). Hence, the larger the value of $h$, the smaller the amount of chattering in the system states.

\section{Detection of Voltage Anomalies and Generation of Compensating Voltage References Using the ANF}

As mentioned in Section III-B, the generation of compensating voltage references $\left(v_{c p}^{*}\right)$ is essential in the SMC. The SMC is solely designed to regulate and balance the load voltage amplitudes at the fundamental frequency. The undistorted and balanced three-phase voltages on the load terminals are given by

$$
\left.\begin{array}{l}
v_{L a}(t)=V_{L a} \sin \left(\omega_{0} t+\phi\right)=230 \sqrt{2} \sin (2 \pi 50 t) \\
v_{L b}(t)=V_{L b} \sin \left(\omega_{0} t+\phi\right)=230 \sqrt{2} \sin \left(2 \pi 50 t-\frac{2 \pi}{3}\right) \\
v_{L c}(t)=V_{L c} \sin \left(\omega_{0} t+\phi\right)=230 \sqrt{2} \sin \left(2 \pi 50 t+\frac{2 \pi}{3}\right)
\end{array}\right\} .
$$

The control of load voltage amplitudes $\left(V_{L p}\right)$ is relatively easy. However, most of the control strategies devised for DVRs may fail under distorted utility voltage conditions. Therefore, an effective method is essential to detect the voltage harmonics. The ANF algorithm is a good candidate to extract the undistorted reference voltages and grid frequency information from the distorted grid [25], [26]. Before adopting the ANF algorithm to the DVR system, we assume that the three-phase grid voltages are distorted by the voltage harmonics and are unbalanced as follows:

$$
\left.\begin{array}{rl}
v_{s a}(t)= & 240 \sqrt{2} \sin \left(\omega_{0} t\right)+30 \sin \left(5 \omega_{0} t\right) \\
& +20 \sin \left(7 \omega_{0} t\right)+7 \sin \left(11 \omega_{0} t\right) \\
v_{s b}(t)= & 226 \sqrt{2} \sin \left(\omega_{0} t-\frac{2 \pi}{3}\right)+35 \sin \left(5 \omega_{0} t-\frac{2 \pi}{3}\right) \\
& +9 \sin \left(7 \omega_{0} t-\frac{2 \pi}{3}\right)+10 \sin \left(11 \omega_{0} t-\frac{2 \pi}{3}\right) \\
v_{s c}(t)= & 247 \sqrt{2} \sin \left(\omega_{0} t+\frac{2 \pi}{3}\right)+19 \sin \left(5 \omega_{0} t+\frac{2 \pi}{3}\right) \\
& +15 \sin \left(7 \omega_{0} t+\frac{2 \pi}{3}\right)+13 \sin \left(11 \omega_{0} t+\frac{2 \pi}{3}\right)
\end{array}\right\}
$$




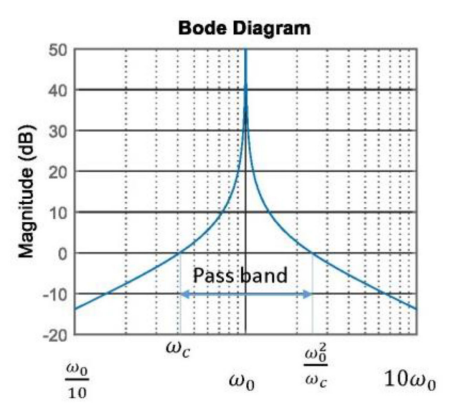

Fig. 3. Bandpass effect of the ANF.

The characteristic time domain model of transfer functions of the ANF is represented as follows:

$$
\left.\begin{array}{l}
\ddot{v}_{s p}(t)=\theta\left[\zeta e_{s p}(t)-\theta v_{s p}(t)\right] \\
\dot{v}_{s p}(t)=v_{s p}(t)-e_{s p}(t) \\
\dot{\theta}=-\gamma v_{s p}(t) \theta e_{s p}(t)
\end{array}\right\}
$$

where $v_{s p}(t)$ is the measured three-phase grid voltages, $\theta$ is the estimated frequency for nominal system frequency $\left(\omega_{0}\right)$, and $\zeta$ and $\gamma$ are the adjustable real positive parameters that, respectively, determine the estimation accuracy and the capability of the algorithm in tracking the grid voltage characteristics variations. The error signal for each phase is defined as $e_{s p}(t)=v_{s p}(t)-\left[V_{L p} \sin \left(\omega_{0} t+\varphi\right)\right]$ and the derivative of the state variable $v_{s p}(t)$ is the fundamental component of the input voltage. For the sake of simplicity, the subscript " $s p$ " is dropped from $e_{s p}(t)$ and $\dot{v}_{s p}(t)$. Hence, the transfer function from $E(s)$ to $\dot{V}(s)$ is given by

$$
G_{e}(s)=\frac{\dot{V}(s)}{E(s)}=\frac{\zeta \theta s}{s^{2}+\theta^{2}}
$$

where $E(s)$ and $\dot{V}(s)$ denote the Laplace transforms of the error signal $e_{s p}(t)$ and derivative of grid voltage $\dot{v}_{s p}(t)$, respectively. Rewriting $G_{e}(s)$ in the frequency domain yields

$$
G_{e}(j \omega)=j \frac{\zeta \omega \theta}{\theta^{2}-\omega^{2}}=\frac{\zeta \omega \theta}{\theta^{2}-\omega^{2}} \angle \pi / 2
$$

where $\omega$ is the angular frequency of the source voltage and $\zeta$ is the damping factor of the ANF algorithm. From (32), when $\omega=\theta,\left\|G_{e}(j \omega)\right\|=\infty$ and the error vanishes according to (31). In other words, the fundamental component can thoroughly pass through the ANF. In order to tune $\zeta$, the system is considered at the steady state as $\theta=\omega_{0}$. Assuming that $\omega_{c}$ is the crossover frequency of the open-loop system (the transfer path from $E(s)$ to $\dot{V}(s))$, the gain of $G_{e}(j \omega)$ at $\omega_{c}$ must be unity:

$$
\left\|G_{e}\left(j \omega_{c}\right)\right\|=\zeta \frac{\omega_{c} \omega_{0}}{\omega_{0}^{2}-\omega_{c}^{2}}=1 .
$$

Solving for $\zeta$ gives

$$
\zeta=\frac{\omega_{0}}{\omega_{c}}-\frac{\omega_{c}}{\omega_{0}}
$$

Fig. 3 shows the bandpass effect of the ANF. It is evident that only the signal whose frequency ranges from $\omega_{c}$ to $\omega_{c}^{2} / \omega_{c}$ is passed through the filter. The rate of convergence of the ANF is proportional to the width of the band:

$$
T_{c} \approx \frac{2 \pi}{\left(\omega_{0}^{2} / \omega_{c}\right)-\omega_{c}}=\frac{2 \pi}{\zeta \omega_{0}} .
$$

It is obvious from (35) that the wider the bandwidth, the faster the rate of convergence can be obtained.

In such a case, the output signal also contains more harmonics whose frequency is close to the fundamental $\omega_{0}$. On the other hand, narrower bandwidth takes longer time to vanish the error signal. However, in this case, the harmonics of the output signal are eliminated mostly. Accordingly, the reasonable value for $\zeta$ should vary between 0.2 and 2 depending on the frequency and the desired quality of the output signal.

Also, there is a need to tune $\gamma$. For this issue, the dynamic model of $\theta$ is

$$
\dot{\theta}=-\gamma v_{s p}(t) e_{s p}(t) \theta=\frac{\gamma}{\zeta} v_{s p}(t)\left[\ddot{v}_{s p}(t)+\theta^{2} v_{s p}(t)\right] .
$$

In the steady state, since $\dot{\theta}=0, \quad \ddot{v}_{s p}(t) \rightarrow \ddot{\bar{v}}_{s p}(t)$, and $v_{s p}(t) \rightarrow \bar{v}_{s p}(t)$, then we have

$$
\left.\begin{array}{l}
\theta=\omega_{0} \\
\ddot{\bar{v}}_{s p}(t)=-\omega_{0}^{2} \bar{v}_{s p}(t)
\end{array}\right\} .
$$

Now, let $\hat{\theta}$ be the small signal component of $\theta . \hat{\theta}$ denotes the small variations of $\theta$ around $\omega_{0}$ such that

$$
\theta=\omega_{0}+\hat{\theta} .
$$

For the initial condition of the integrator, $\omega_{0}$ is set to $100 \pi$. From (36) and (37), the small signal model can be written as

$$
\dot{\hat{\theta}}=-\frac{\gamma}{\zeta} \bar{v}_{s p}^{2}(t)\left(\hat{\theta}^{2}+2 \hat{\theta} \omega_{0}\right)
$$

Since $\hat{\theta}$ is a small signal, $\hat{\theta}^{2}$ can be neglected. Therefore, the model in (39) reduces to

$$
\dot{\hat{\theta}}=-\frac{2 \gamma \omega_{0} \hat{\theta}}{\zeta} \bar{v}_{s p}^{2}(t)
$$

Once the system (40) is stable, its eigenvalue $(\sigma)$ must be placed at the left half-plane of the Re-Im surface, where

$$
\sigma=-\frac{2 \gamma \omega_{0}}{\zeta} \bar{v}_{s p}^{2}(t)
$$

From another aspect, if the fundamental of $v_{s p}(t)$ is

$$
v_{s p}(t)=V_{s p} \sin \left(\omega_{0} t\right)
$$

then the state variable $\bar{v}_{s p}(t)$ is given by

$$
\bar{v}_{s p}(t)=\frac{V_{s p}}{\omega_{0}} \cos \left(\omega_{0} t\right) .
$$

Substituting (43) into (41) yields

$$
\sigma=-\frac{2 \gamma \omega_{0}}{\zeta}\left(\frac{V_{s p}}{\omega_{0}}\right)^{2} \cos ^{2}\left(\omega_{0} t\right)
$$

where $\omega_{0}$ is the angular (center) frequency of the source voltage. By assigning

$$
\gamma=\frac{\zeta}{2}\left(\frac{\omega_{0}}{V_{s p}}\right)^{2}
$$




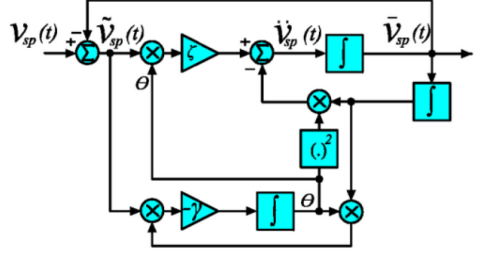

Fig. 4. Block diagram of the proposed ANF.

the eigenvalue $\sigma$ is placed around $-\omega_{0}$. As a consequence, the system is always stable with the rate of convergence proportional to $2 \pi / \omega_{0}$. In addition, the stability of the proposed system (both ANF and SMC) is not degraded when the compensating voltage reference is generated inaccurately. In this case, as mentioned just after (35), the ANF cannot produce the desired compensating voltage reference immediately after the occurrence of the voltage sag (or swell). Eventually, the dynamic response of the controller becomes faster (or slower) depending on the value of $\zeta$. In order to investigate the performance of SMC, let the inaccurate compensating voltage reference be determined by

$$
\hat{v}_{c p}^{*}=v_{c p}^{*}+\varepsilon
$$

where $\varepsilon$ denotes the error involved in the compensating voltage reference. Substituting (46) into (3) and (9) yields

$$
\begin{aligned}
\hat{x}_{1 p} & =x_{1 p}-\varepsilon, \quad \hat{x}_{2 p}=x_{2 p}-\dot{\varepsilon} \\
\hat{D}_{p}(t) & =D_{p}(t)-(\varepsilon+L C k \dot{\varepsilon}) / V_{\mathrm{dc}} .
\end{aligned}
$$

Now, substituting (47) and (48) into (15) and (16) gives

$$
\begin{aligned}
l_{1 p}= & -\omega_{s}^{2} x_{1 p}+\lambda x_{2 p}+d_{1 p}(t)+\omega_{s}^{2} \varepsilon-\lambda \dot{\varepsilon} \\
& -\frac{1}{V_{\mathrm{dc}}}(\varepsilon+L C k \dot{\varepsilon})>0 \\
l_{2 p}= & -\omega_{s}^{2} x_{1 p}+\lambda x_{2 p}+d_{2 p}(t)+\omega_{s}^{2} \varepsilon-\lambda \dot{\varepsilon} \\
& -\frac{1}{V_{\mathrm{dc}}}(\varepsilon+L C k \dot{\varepsilon})<0 .
\end{aligned}
$$

$l_{1 p}$ and $l_{2 p}$ represent two parallel lines, which determine the boundaries of the stability region in the reaching mode in $x_{1 p}-x_{2 p}$ plane (not shown due to limited space). Comparing (15) and (16) with (49) and (50), one can see that the intersection points of (49) and (50) have additional terms due to $\varepsilon$. This means that the stability region still exists, but its borders are changed slightly. On the other hand, when the system enters into the sliding mode with $\hat{v}_{c p}^{*}$, (11) becomes $\hat{\dot{x}}_{1 p}=-\lambda \hat{x}_{1 p}$ whose solution $\hat{x}_{1 p}=\hat{x}_{1 p}(0) e^{-\lambda t}$ depends neither on the system parameters nor the disturbance. In this case, $\hat{x}_{1 p}$ converges to zero (which means that $x_{1 p}=\varepsilon$ ) without any stability problem. Simulation and experimental results presented in Sections IV and V verify that the stability is not degraded when the ANF generates inaccurate compensating voltage reference during the occurrence of voltage sag. The block diagram of the proposed ANF is shown in Fig. 4. The consequence of using the ANF eliminates the use of phaselock loop (PLL), frequency-lock loop (FLL) and low-pass filter (LPF), which makes it distinguishable from the existing

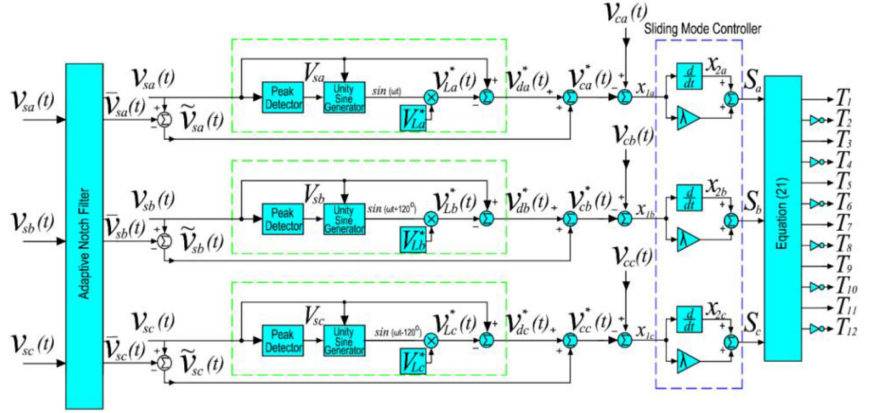

Fig. 5. Block diagram of the proposed control strategy.

reference signal generation methods such as second-order generalized integrator and self-tuning filter used in [17] and [19], respectively.

In order to determine the voltages that involve the anomalies, the source voltages generated with the ANF algorithm are subtracted from the measured source voltages as follows:

$$
\tilde{v}_{s p}(t)=v_{s p}(t)-\bar{v}_{s p}(t) .
$$

The voltage difference for each phase can be determined by subtracting the reference load voltage waveform from the measured source voltage as follows:

$$
v_{d p}(t)=v_{s p}(t)-v_{L p}^{*}(t) .
$$

The total compensating voltage reference is obtained by adding the voltage harmonic components obtained from (51) to the voltage difference obtained from (52) as follows:

$$
v_{c p}^{*}(t)=\tilde{v}_{s p}(t)+v_{d p}(t) .
$$

The total compensating voltage reference for each phase can be used as a reference input to the SMC, which is discussed in the previous section.

\section{Simulation REsults}

The performance of the proposed control strategy has been tested by simulations using MATLAB/Simulink. The block diagram of the closed-loop system is shown in Fig. 5. The system and control parameters used in the simulation and experimental studies are given in the Appendix. Performance of the proposed control method with the control methods in [18] and [19] is compared under four different grid voltage conditions (case 1, case 2 , case 3 , and case 4 ). In case 1 , it is assumed that a balanced voltage sag occurs (from 230 to $150 \mathrm{~V}$ ) in all phases of the grid voltage for $50 \mathrm{~ms}$. In case 2 , it is assumed that an unbalanced voltage sag occurs in phases A and B of the grid for $50 \mathrm{~ms}$. In case 3 , the voltage swell of $120 \%$ (from 230 to $276 \mathrm{~V}$ ) occurs in phases A and B of the grid for $50 \mathrm{~ms}$. Finally, in case 4, the grid voltage (all phases) is assumed to be highly distorted for $50 \mathrm{~ms}$. The simulation results regarding these conditions are shown in Fig. 6(a).

Fig. 6 shows the simulation results obtained from the methods in [18] and [19] and the proposed control method during the grid voltage conditions described above. While Fig. 6(b) and (e) belongs to the method in [18], Fig. 6(c) and (f) belongs 


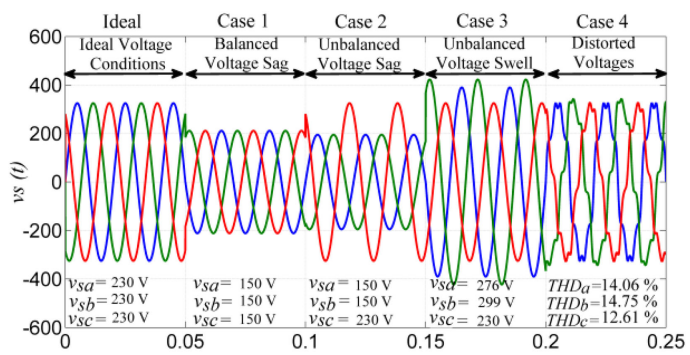

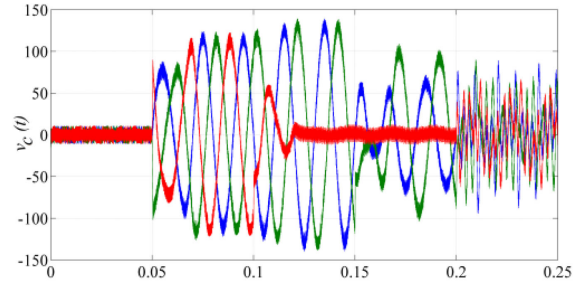

(b)

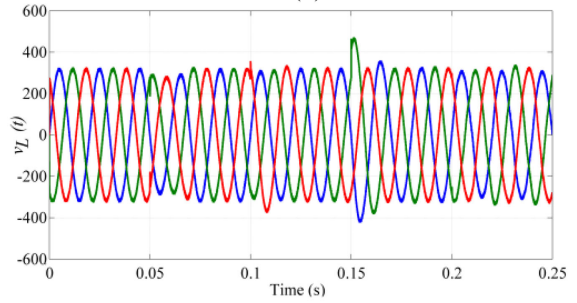

(e) (a)

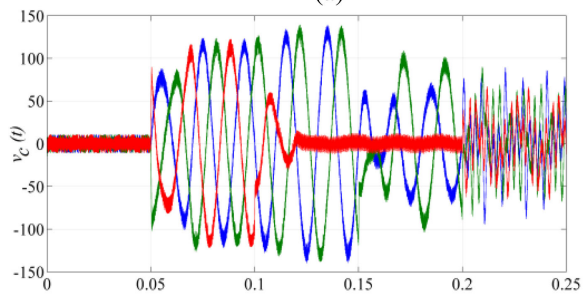

(c)

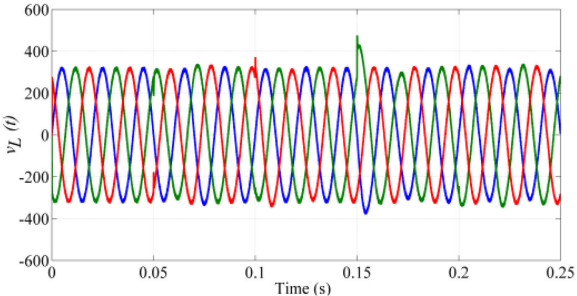

(f)

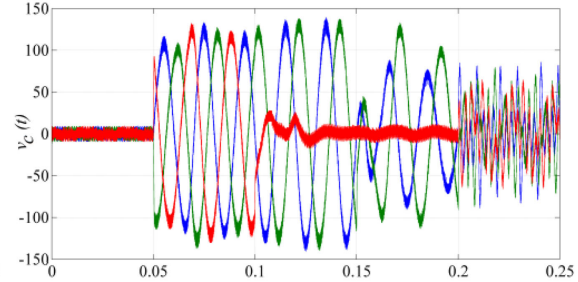

(d)

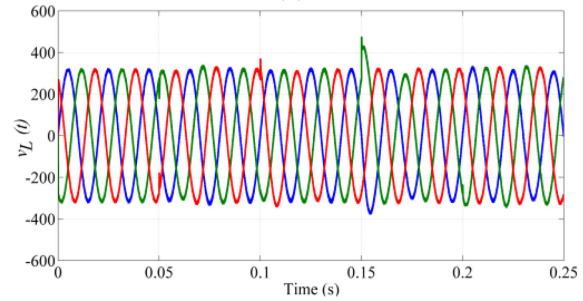

(g)

Fig. 6. Simulation results under (a) various grid voltage anomalies, and obtained results with the methods presented in [18] (b) and (e), [19] (c) and (f), and proposed control method (d) and (g).

to the method in [19]. The results obtained with the proposed method are shown in Fig. 6(d) and (g). The balanced voltage sag described in case 1 starts at $t=0.05 \mathrm{~s}$ and lasts until $t=$ $0.1 \mathrm{~s}$, as shown in Fig. 6(a). Despite 65\% voltage sag, the load voltages were compensated dynamically in all phases, as shown in Fig. 6(e)-(g). The unbalanced voltage sag described in case 2 starts at $t=0.1 \mathrm{~s}$ and lasts until $t=0.15 \mathrm{~s}$, as shown in Fig. 6(a). Note that the grid voltage at phase-C is not changed during this interval. Again, the load voltages for phases A and B were compensated successfully, as shown in Fig. 6(e)-(g). It is evident that the VSI does not produce any compensation voltage for phase-C, as shown in Fig. 6(b)-(d). The voltage swell condition described in case 3 starts at $t=0.15 \mathrm{~s}$ until $t=0.2 \mathrm{~s}$, as shown in Fig. 6(a). It is shown in Fig. 6(b)-(d) that the DVR injects the necessary compensation voltages to phases A and B to keep the load voltages at the desired level. Performance of the proposed control strategy was also tested under distorted grid voltage condition described in case 4. As shown in Fig. 6(a), the three-phase grid voltages after $t=0.2 \mathrm{~s}$ are highly distorted. The THD of the grid voltages in each phase is computed as $14.06 \%, 14.75 \%$, and $12.61 \%$. Despite the highly distorted grid voltages, the DVR injects the required compensating voltages to suppress the voltage harmonics before they reach to the load terminals. As a consequence of this harmonic suppression, the load voltages were maintained at the desired level.

Comparing Fig. 6(b), (c), (e), and (f) with Fig. 6(d) and (g), the dynamic response of the proposed control method is seen to be much faster than that proposed in [18] and [19] during case 1. Although the performances of these control methods are comparable under the other grid conditions, the proposed control with the ANF yields a simpler structure due to its advantage that does not require PLL.

Fig. 7 shows the sliding surface function and state trajectory in the phase plane (phase A only) under case 1. It is shown in Fig. 7(a) that the sliding surface function is bounded by the hysteresis bands, which are introduced to limit the chattering. In the start-up, both state variables $\left(x_{1 \mathrm{a}}\right.$ and $\left.x_{2 \mathrm{a}}\right)$ are zero, as shown in Fig 7(b). When the system starts, the trajectory moves away from the equilibrium point in the negative direction until it reaches to the sliding line $\left(S_{\mathrm{a}}=0\right)$ where the sliding mode operation is started. Thereafter, the trajectory moves along the sliding line by making zigzag motions until the equilibrium point is reached, as shown in Fig. 7(c). It is worth noting that the effect of the voltage sag condition is not shown in Fig. 7(c) due to the fast response of the controller.

\section{EXPERIMENTAL RESULTS}

In order to observe the performance in a real-time environment, the 12-switch DVR with the proposed control strategy has been modeled in Simulink using OPAL-RT real-time platform and associated tools. The system is then tested with a hardware synchronization mode to obtain the real-time communications among the sensing and control signals. The OPAL-RT 


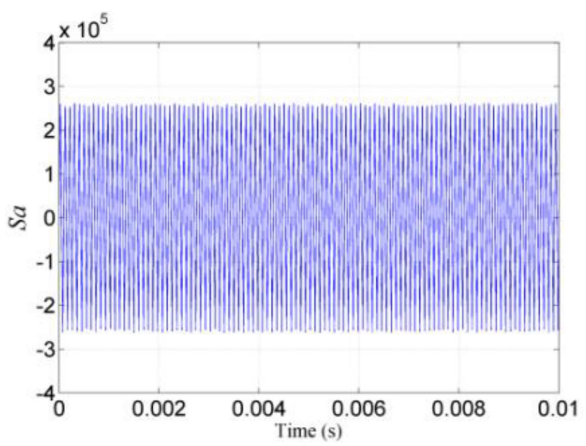

(a)

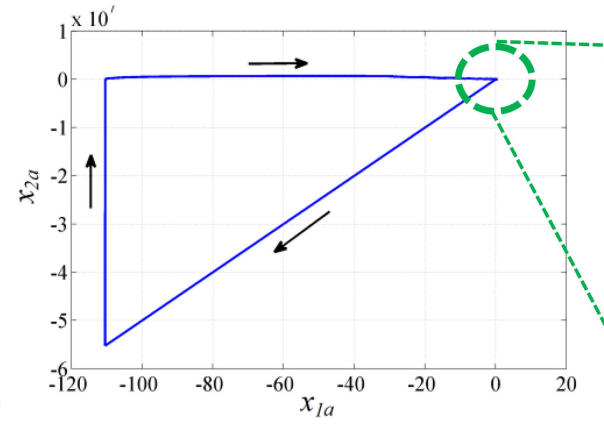

(b)

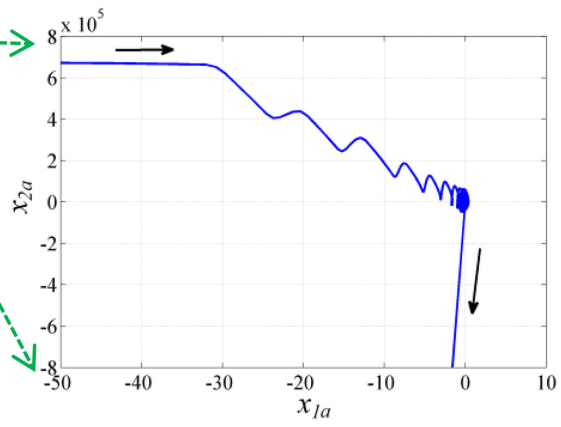

(c)

Fig. 7. (a) Sliding surface function. (b) State trajectory for start-up and case 1 in the phase-plane. (c) Magnified view of the trajectory in (b).

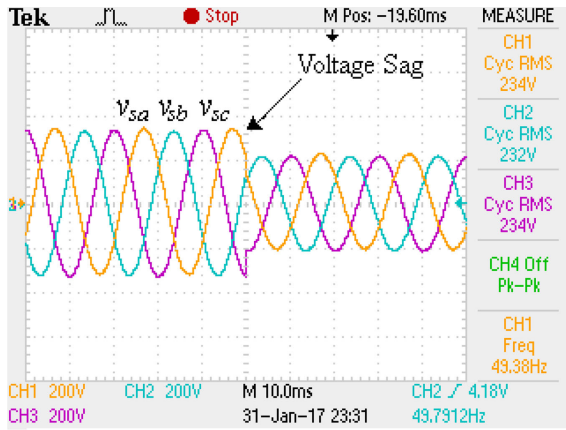

(a)

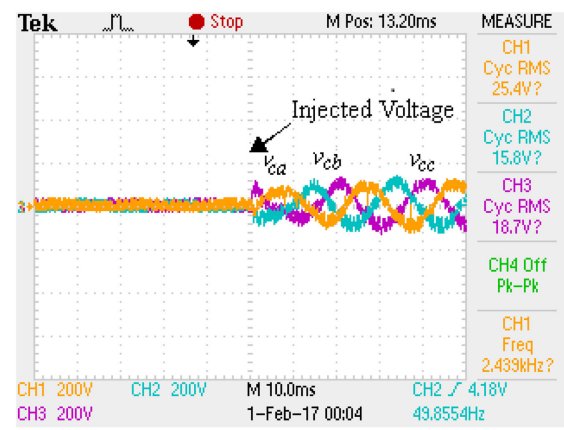

(b)

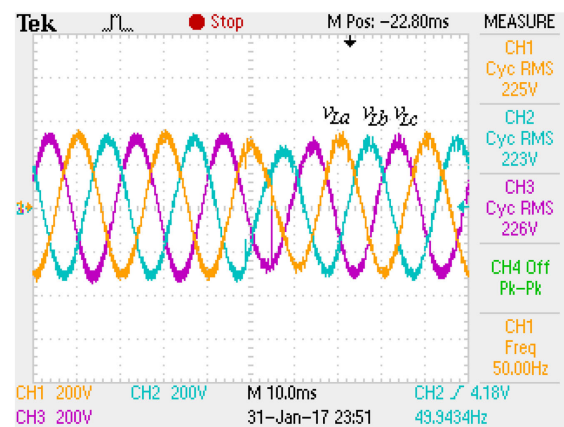

(c)

Fig. 8. Experimental results for case 1. (a) Grid voltages. (b) Injected voltages. (c) Load voltages.

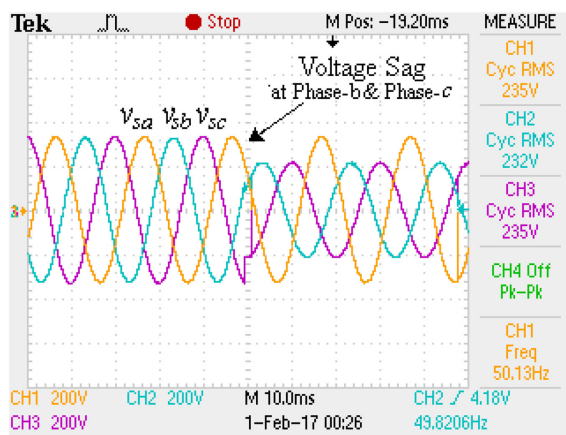

(a)

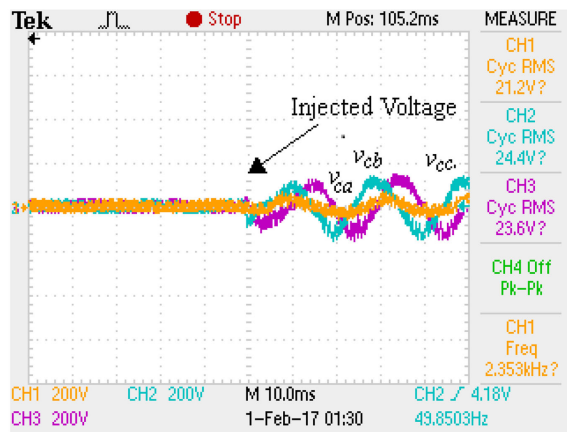

(b)

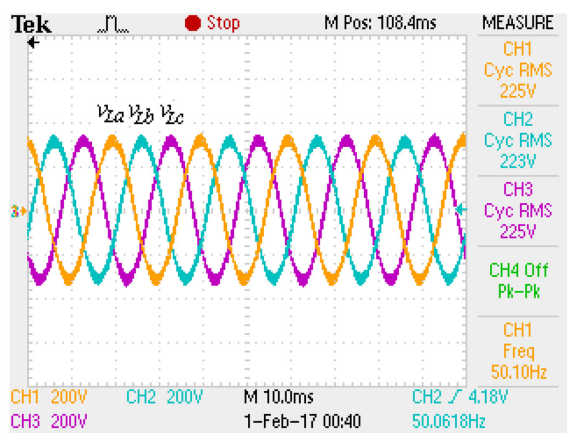

(c)

Fig. 9. Experimental results for case 2. (a) Grid voltages. (b) Injected voltages. (c) Load voltages.

is a real-time simulation platform working under RT-LAB software environment. It has 16 analog inputs and outputs, and 32 digital inputs and outputs.

Figs. 8-12 shows the real-time results that correspond to the simulation results in Fig. 6. Fig. 8(a) shows the three-phase voltage sags [from $230 \mathrm{~V}$ (rms) to $150 \mathrm{~V}$ (rms)] that occur on the grid voltage for case 1 . When the voltage sags occur, the DVR injects the required compensation voltages into the PCC through the series transformers, as shown in Fig. 8(b). As a result of this, the effects of voltage sags on the load terminals are strongly eliminated, as displayed in Fig. 8(c). Fig. 9(a) shows the voltage sags (voltage is reduced from 230 to $150 \mathrm{~V}$ ) that occur at phase-A and phase-B for case 2. Fig. 9(b) shows that the DVR injects the compensation voltages for phase-A and phase-B so as to maintain the load voltages at the desired level, as shown in Fig. 9(c). This case shows that the proposed control strategy has a strong ability to operate independently from the phases.

The voltage swells existing on phase-B and phase- $\mathrm{C}$ (for case 3) are shown in Fig. 10(a). Despite this swell condition, the DVR successfully injects the required voltages, as shown in Fig. 10(b), and achieves the compensation of the load voltages, as shown in Fig 10(c). It is worth to note that the DVR does not generate a compensation voltage for phase-A because there was no voltage swell for this phase.

Fig. 11(a) shows highly distorted and unbalanced grid voltages, for case 4 , together with their measured THD values. 


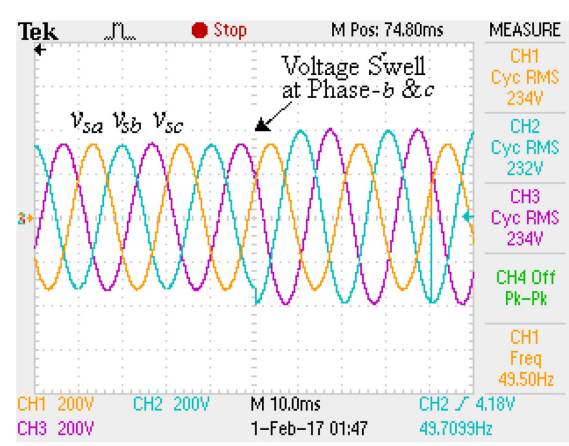

(a)

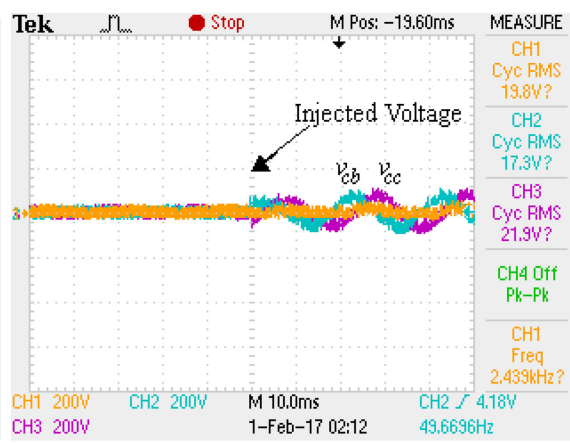

(b)

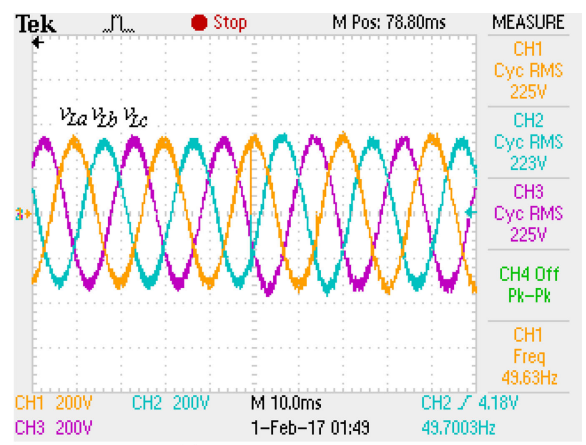

(c)

Fig. 10. Experimental results for case 3. (a) Grid voltages. (b) Injected voltages. (c) Load voltages.

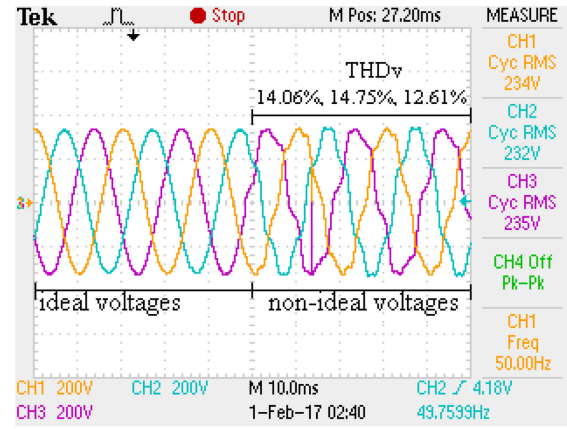

(a)

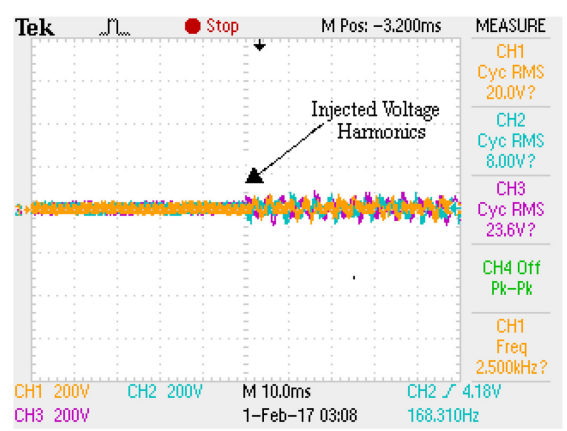

(b)

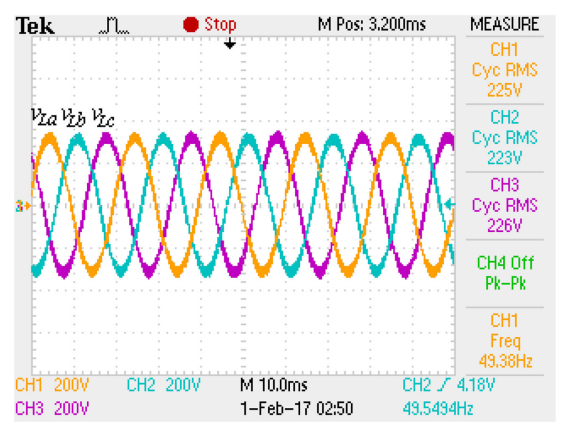

(c)

Fig. 11. Experimental results for case 4. (a) Grid voltages. (b) Injected voltages. (c) Load voltages.

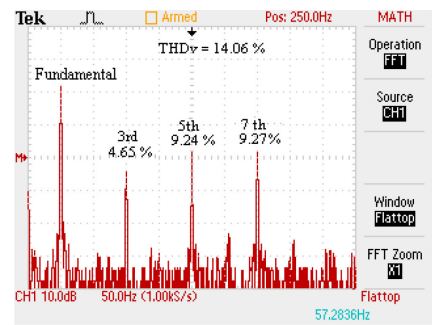

(a)

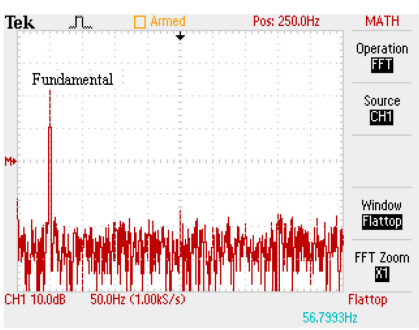

(b)
Fig. 12. Voltage harmonic spectrums for case 4 at phase-A. (a) Grid voltage. (b) Load voltage.

The injected and load voltages are shown in Fig. 11(b) and (c), respectively. Despite the highly distorted grid voltage, the proposed control method reduces the load voltage THD to $2 \%$ (see Fig. 12), thereby satisfying the IEEE 519-1992 standards on the harmonic limits [27].

The harmonic spectra of the grid and load voltages for case 4 are shown in Fig. 12(a) and (b), respectively. It is evident that third, fifth, and seventh harmonic components do not appear in the harmonic spectrum of the load voltage.

\section{Comparisons of the Proposed Method With the STATE-OF-THE-ART}

It is well-known that the occurrence and intensity of voltagerelated power quality problems are increasing in the grid. This is due to the increase in the number of voltage harmonic- generating devices. In order to overcome these voltage-related power quality problems, several DVR topologies and control methods have been investigated in the literature. A comparison of the proposed method with the state-of-the-art systems in terms of the various features of each method is presented in Table I. The first drawback of the methods presented in [6], [28], and [29] is that they need PLL or FLL or LPF in generating the compensating voltage references, which increase the complexity. The proposed controller does not have such problem as the ANF generates the compensating voltage references without using PLL, FLL, and LPF. The second drawback of these methods is that they compensate for voltage sags and swells only. In these studies, no result is provided to demonstrate the performance of the controller under a distorted grid condition. In contrast, the proposed method not only compensates voltage sags/swells but also suppresses voltage harmonics on the load terminals and mitigates grid disturbances.

On the other hand, while methods in [28] and [29] require a dc-link capacitor to be connected at the input of the inverter, the method in [6] and proposed method require a dc source (battery). The stored energy in the dc-link capacitor may not be sufficient to feed the inverter when the duration of voltage sags/swells is long, which degrades the performance of the DVR. Although the stored energy in the dc-link capacitor can be increased by selecting a large capacitor, this increases the cost and, therefore, a compromise between cost and compensation duration should be considered. Furthermore, the computations needed in these control algorithms are high due to the fact that they need $a b c / d q$ and 
TABLE I

Comparisons of the Proposed Control Method With Other Methods

\begin{tabular}{|c|c|c|c|c|}
\hline Comparison Category & {$[6]$} & {$[28]$} & [29] & Proposed Method \\
\hline Inverter topology & 12-Switch & 12-Switch & 12-Switch & 12-Switch \\
\hline Detection and reference generation & $\begin{array}{l}\text { Synchronous reference } \\
\text { frame }\end{array}$ & $\begin{array}{l}\text { Synchronous } \\
\text { reference frame }\end{array}$ & Fuzzy logic & Adaptive notch filter \\
\hline Control strategy & Fuzzy logic & $\begin{array}{c}\text { Hysteresis } \\
\text { voltage control }\end{array}$ & $\begin{array}{l}\text { Proportional-integral } \\
\text { control }\end{array}$ & SMC \\
\hline Ability of sag compensation & Yes & Yes & Yes & Yes \\
\hline Ability of swell compensation & Yes & No & No & Yes \\
\hline Ability of harmonic voltage compensation & No & Yes & No & Yes \\
\hline $\begin{array}{c}\text { Ability of unbalanced voltage } \\
\text { compensation }\end{array}$ & Yes & Yes & No & Yes \\
\hline Energy storage & Battery & Capacitor & Capacitor & Battery \\
\hline Dynamic response & Slow & Fast & Fast & Fast \\
\hline Compensation duration & High & Limited & Limited & High \\
\hline Implementation complexity & Complicated & Complicated & Complicated & Simple \\
\hline Cost of the system & Medium & Medium & Medium & Low \\
\hline
\end{tabular}

$d q / a b c$ transformations [6], [28] and fuzzy rule base [6], [29]. Hence, the implementation of the proposed control method is reasonably simpler and computationally efficient than the aforementioned methods. In addition, the methods proposed in [6], [28], and [29] require three, ten, and six sensors, respectively, for measuring the voltages and currents needed in the control algorithm. Although the proposed control method requires six voltage sensors, its cost is less than the aforementioned methods when its implementation simplicity and computational requirements are considered. Finally, owing to the inherent feature of SMC, the proposed control method exhibits a fast dynamic response, which is comparable to that of other methods.

\section{CONCLUSION}

In this paper, an SMC strategy was proposed for the threephase DVR using the 12-switch VSI. Different from the existing methods, the compensating voltage references required in the SMC were generated by an ANF, which showed excellent performance under grid voltage anomalies such as voltage sags, swells, and unbalanced and distorted voltage conditions. Unlike existing reference signal generation solutions, the proposed ANF did not require PLL or FLL and LPF. Moreover, the use of SMC with its attractive properties made the control implementation simple. Theoretical considerations were verified by the simulation results as well as the real-time laboratory results over a range of grid voltage anomalies. These results showed that the proposed control strategy not only offers an excellent dynamic response independent from the parameter variations and disturbances but also compensates the voltage sags, swells, and harmonics on the load terminals.

\section{APPENDIX}

The system and control parameters of the analyzed test system for both simulation and experimental are as follows: $V_{s p}=$ $230 \sqrt{2} \mathrm{~V}, V_{\mathrm{dc}}=600 \mathrm{~V}, L=0.35 \mathrm{mH}, C=150 \mu \mathrm{F}, \operatorname{Load}_{1}=$ $4 \Omega+10 \mathrm{mH}, \operatorname{Load}_{2}=24 \Omega+15 \mathrm{mH}, \lambda=4714, \zeta=0.6$, and $\gamma=18000$. The sampling time is $35 \mu \mathrm{s}$.

\section{REFERENCES}

[1] M. Ramasamy and S. Thangavel, "Experimental verification of PV based dynamic voltage restorer with significant energy conservation," Electr. Power Energy Syst., vol. 49, pp. 296-307, Jul. 2013.

[2] N. G. Jayanti, M. Basu, I. Axente, K. Gaughan, and M. F. Conlon, "Sequence analysis based DSP controller for dynamic voltage restorer (DVR)," in Proc. IEEE Power Electron. Spec. Conf., Rhodes, Greece, Jun. 2008, pp. 3986-3991.

[3] A. M. Rauf and V. Khadkikar, "An enhanced voltage sag compensation scheme for dynamic voltage restorer," IEEE Trans. Ind. Electron., vol. 62, no. 5, pp. 2683-2692, May 2015

[4] S. Biricik, S. K. Khadem, S. Redif, and M. Basu, "Control of the dynamic voltage restorer to improve voltage quality," in Proc. 5th Int. Symp. Power Electron. Distrib. Gener. Syst., Galway, Ireland, 2014, pp. 1-5.

[5] V. D. Mahinda, H. M. Wijekoon, and S. S. Choi, "A novel dynamic series compensator with closed-loop voltage and current mode control for voltage sag mitigation," Int. J. Electron., vol. 90, pp. 695-706, 2003.

[6] A. Teke, K. Bayindir, and M. Tumay, "Fast sag/swell detection method for fuzzy logic controlled dynamic voltage restorer," IET Gener. Transm. Distrib., vol. 4, no. 1, pp. 1-12, Jan. 2010

[7] F. A. L. Jowder, "Design and analysis of dynamic voltage restorer for deep voltage sag and harmonic compensation," IET Gener. Transm. Distrib. vol. 3, no. 6, pp. 547-560, Jun. 2009.

[8] P. Jayaprakash, B. Singh, D. P. Kothari, A. Chandra, and K. Al-Haddad, "Control of reduced-rating dynamic voltage restorer with a battery energy storage system," IEEE Trans. Ind. Appl., vol. 50, no. 2, pp. 1295-1303, Mar./Apr. 2014.

[9] H. Abdollahzadeh, M. Jazaeri, and A. Tavighi, "A new fast-converged estimation approach for dynamic voltage restorer (DVR) to compensate voltage sags in waveform distortion conditions," Int. J. Electr. Power Energy Syst., vol. 54, pp. 598-609, Jan. 2014.

[10] B. Bae, J. Lee, J. Jeong, and B. Han, "Line-interactive single-phase dynamic voltage restorer with novel sag detection algorithm," IEEE Trans. Power Del., vol. 25, no. 4, pp. 2702-2709, Oct. 2010.

[11] N. D. Tuyen, G. Fujita, M. N. B. Muhtazaruddin, and T. Funabashi, "Shunt active power filter for 3-phase 3-wire nonlinear load under unbalanced and distorted PCC voltage using notch adaptive filter," in Proc. IEEE PES T\&D Conf. Expo., 2014, pp. 1-5

[12] N. D. Dinh, N. D. Tuyen, G. Fujita, and T. Funabashi, "Adaptive notch filter solution under unbalanced and/or distorted point of common coupling voltage for three-phase four-wire shunt active power filter with sinusoidal utility current strategy," IET Gener. Transm. Distrib., vol. 9, no. 13 , pp. $1580-1596,2015$.

[13] O. Kukrer, H. Komurcugil, and A. Doganalp, "A three-level hysteresis function approach to the sliding mode control of single-phase UPS inverters," IEEE Trans. Ind. Electron., vol. 56, no. 9, pp. 3477-3486, Sep. 2009

[14] H. Komurcugil, "Rotating-sliding-line-based sliding-mode control for single-phase UPS inverters," IEEE Trans. Ind. Electron., vol. 59, no. 10, pp. 3719-3726, Oct. 2012. 
[15] H. Komurcugil, "Adaptive terminal sliding-mode control strategy for dcdc buck converters," ISA Trans., vol. 51, no. 6, pp. 673-681, Nov. 2012.

[16] H. Komurcugil, "Non-singular terminal sliding-mode control of dc-dc buck converters," Control Eng. Pract., vol. 21, no. 3, pp. 321-332, Mar. 2013.

[17] S. Biricik, H. Komurcugil, and M. Basu, "Sliding mode control strategyfor three-phase DVR employing twelve-switch voltage source converter," in Proc. 41st Annu. Conf. IEEE Ind. Electron. Soc., 2015, pp. 921-926.

[18] H. Komurcugil and S. Biricik, "Time-varying and constant switching frequency-based sliding-mode control methods for transformerless DVR employing half-bridge VSI," IEEE Tran. Ind. Electron., vol. 64, no. 4, pp. 2570-2579, Apr. 2017

[19] S. Biricik and H. Komurcugil, "Optimized sliding mode control to maximize existence region for single-phase dynamic voltage restorers," IEEE Trans. Ind. Inform., vol. 12, no. 4, pp. 1486-1497, Aug. 2016.

[20] Z. Changjiang et al., "Dynamic voltage restorer based on voltage-spacevector PWM control," IEEE Trans. Ind. Appl., vol. 37, no. 6, pp. 18551863, Nov./Dec. 2001.

[21] C. J. Zhan et al., "Two electrical models of the lead-acid battery used in a dynamic voltage restorer," IEE Proc., Gener. Transm. Distrib., vol. 150, no. 2, pp. 175-182, 2003

[22] V. K. Ramachandaramurthy, C. Fitzer, A. Arulampalam, C. Zhan, M. Barnes and N. Jenkins, "Control of a battery supported dynamic voltage restorer," IEE Proc., Gener. Transm. Distrib., vol. 149, no. 5, pp. 533-542, 2002.

[23] P. Jayaprakash, B. Singh, D. P. Kothari, A. Chandra, and K. Al-Haddad, "Control of reduced-rating dynamic voltage restorer with a battery energy storage system," IEEE Trans. Ind. Appl., vol. 50, no. 2, pp. 1295-1303, Mar./Apr. 2014

[24] E. Babaei and M. F. Kangarlu, "Comparison four topologies for threephase dynamic voltage restorer," in Proc. IEEE Int. Conf. Renew. Energy Res. Appl., 2015, pp. 1527-1532.

[25] M. Mojiri, M. Karimi-Ghartemani, and A. Bakhshai, "Time-domain signal analysis using adaptive notch filer," IEEE Trans. Signal Process., vol. 55, no. 1, pp. 85-93, Jan. 2007.

[26] D. Yazdani, M. Mojiri, A. Bakhshai, and G. Joos, "A fast and accurate synchronization technique for extraction of symmetrical components," IEEE Trans. Power Electron., vol. 24, no. 3, pp. 674-684, Mar. 2009.

[27] IEEE Recommended Practices and Requirements for Harmonic Control in Electrical Power Systems, IEEE Standard 519-1992, pp. 1-112, 1993.

[28] P. Kanjiya, B. Singh, A. Chandra, and K. Al-Haddad, "SRF theory revisited" to control self-supported dynamic voltage restorer (DVR) for unbalanced and nonlinear loads," IEEE Trans. Ind. Appl., vol. 49, no. 5, pp. 2330-2340, Sep./Oct. 2013.

[29] M. Danbumrungtrakul, T. Saengsuwan, and P. Srithorn, "Evaluation of DVR capability enhancement-zero active power tracking technique," IEEE Access, vol. 5, pp. 10285-10295, 2017.

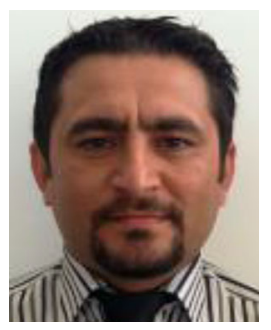

Samet Biricik (M'12) received the B.Sc. and Ph.D. degrees in electrical and electronic engineering from the Near East University, Nicosia, Turkey, in 2006 and 2013, respectively.

From 2006 to 2018, he worked in various industrial and commercial projects. He is currently a Research Fellow with the School of Electrical and Electronic Engineering, Dublin Institute of Technology, Dublin, Ireland, and a Lecturer with the European University of Lefke, Lefke, Turkey. Since 2018, he has been a Member of the boards of directors in the Chamber of Electrical Engineers, North Cyprus. His research interests include the application of power electronics, power quality, electrical machines, and high-voltage engineering.

Dr. Biricik was a recipient of the Best Paper Award from the IEEE 9th International Conference on Environment and Electrical Engineering in 2010.

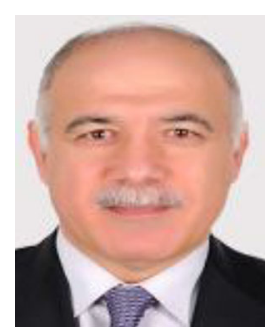

Hasan Komurcugil (S'94-M'99-SM'12) received the B.Sc., M.Sc., and Ph.D. degrees in electrical engineering from the Eastern Mediterranean University (EMU), Famagusta, Turkey, in 1989, 1991, and 1998, respectively.

In 1998, he as an Assistant Professor joined the Computer Engineering Department, EMU, where he was promoted to Associate Professor and Professor positions in 2002 and 2008, respectively. From 2004 to 2010, he was the Head of the Computer Engineering Department, EMU. In 2010, he played an active role in preparing the department's first self-study report for the use of Accreditation Board for Engineering and Technology. He is currently a full-time Professor with the Computer Engineering Department, EMU, and the Board Member of the Higher Education, Planning, Evaluation, Accreditation and Coordination Council North Cyprus. His research interests include power electronics and innovative control methods for power converters.

Dr. Komurcugil was a recipient of Best Presentation Recognitions at the 41st and 42nd Annual Conferences of the IEEE Industrial Electronics Society in 2015 and 2016, respectively. He is a corresponding Guest Editor for Emerging Electric Machines and Drives for Smart Energy Conversion in the IEEE TRANSACTIONS ON ENERGY CONVERSION. Also, he is an Associate Editor for the IEEE TRANSACTIONS ON INDUSTRIAL ELECTRONICS and IEEE TRANSACTIONS ON INDUSTRIAL INFORMATICS.

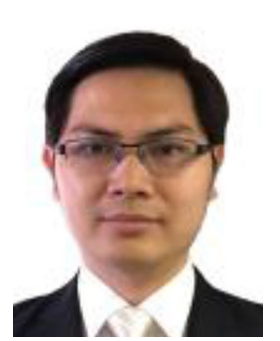

Nguyen Duc Tuyen received the B.S. degree in electrical engineering from Hanoi University of Science and Technology, Hanoi, Vietnam, in 2006, and the M.S. and Ph.D. degrees in electrical engineering from the Shibaura Institute of Technology, Tokyo, Japan, in 2009 and 2012, respectively.

He was a postdoctoral Fellow with the Shibaura Institute of Technology, from 2012 to 2014. From 2014 to 2015, he was a Visiting Researcher with the Shibaura Institute of Technology. From 2015 to 2017, he was a Project Fellow with the Tokyo University of Science, Tokyo, Japan. From 2017 to 2018, he was a Researcher with the National Institute of Advanced Industrial Science and Technology, Tokyo, Japan. Since 2018, he has been with Hanoi University of Science and Technology. His current research interests include distribution power systems, power electronics, renewable energy, smart grids, and hydrogen society.

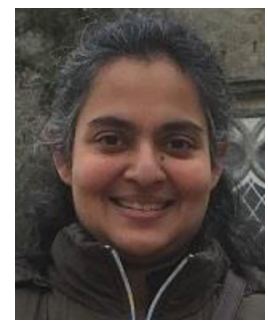

Malabika Basu (S'99-M'03) received the B.E. and M.E. degrees from Bengal Engineering College, Shibpur, India, in 1995 and 1997, respectively, and the Ph.D. degree from the Indian Institute of Technology, Kanpur, India, in 2003, all in electrical engineering.

From 2001 to 2003 , she was a Lecturer with Jadavpur University, Kolkata, India. From 2003 to 2006, she was an Arnold F. Graves Postdoctoral Fellow with Dublin Institute of Technology, Dublin, Ireland, where she has been a Lecturer from 2006, and a Senior Lecturer since 2016. She has authored or coauthored more than 90 technical publications in various international journals and conference proceedings. Her research interests include grid integration of renewable energy sources, power quality conditioners and power quality control and analysis, photovoltaics and wind energy conversion, and smart grid and microgrids. 